\title{
The effect of group size on the speed of decision making depends on compromise and predation risk across populations in the guppy Poecilia reticulata
}

\author{
Amy S.I. Wade ${ }^{a}$, Indar W. Ramnarine ${ }^{b}$ and Christos C. Ioannou ${ }^{a, *}$ \\ ${ }^{\text {a }}$ School of Biological Sciences, University of Bristol, Bristol BS81TQ, UK \\ ${ }^{\mathrm{b}}$ Department of Life Sciences, The University of the West Indies, St. Augustine, Trinidad \& \\ Tobago \\ *Corresponding author's e-mail address: c.c.ioannou@bristol.ac.uk
}

Received 11 April 2020; initial decision 4 July 2020; revised 27 September 2020; accepted 29 September 2020; published online 9 October 2020

\begin{abstract}
While larger groups tend to be better at making decisions, very few studies have explored how ecological variables, including predation pressure, shape how group size affects decision making. Our cross-population study of wild-caught guppies (Poecilia reticulata) shows that leading individuals from larger groups made faster decisions when deciding to leave the start area and reach the junction of a Y-maze, which allows for compromise over timing. However, at the junction of the $\mathrm{Y}$ when the fish needed to make a mutually exclusive decision that does not allow for compromise, there was no effect of group size in high predation fish on decision speed. In fish from low predation habitats, speed was fastest at the intermediate group size with a decline in speed in the largest group size. These results challenge the view that decision making always improves with group size and shows this effect depends on ecological and decision-making conditions.
\end{abstract}

\section{Keywords}

group decision-making, swarm intelligence, collective intelligence, group performance, pool of competence, cross-population, optimal group size, Y-maze.

\section{Introduction}

Living in groups provides a number of benefits for animals, and the independent evolution of group living in numerous taxa suggests that the benefits often outweigh the associated costs (Krause \& Ruxton, 2002; Ioannou, 
2017a). In tasks that are based on uncertain information, such as detecting cues associated with predators or food, making decisions in a group can be beneficial as group living allows individuals to use information from others in the group to find food and other resources (Pitcher et al., 1982; Day et al., 2001; Sasaki et al., 2013) or to avoid predators (Godin et al., 1988; Ward et al., 2011). Consistent with this, numerous studies have shown improved task performance by larger groups in both humans (Koriat, 2012; Ioannou et al., 2018) and other vertebrates (Tamm, 1980; Ranta \& Juvonen, 1993; Liker \& Bókony, 2009; Morand-Ferron \& Quinn, 2011; Ward et al., 2011; Berdahl et al., 2013).

There are three non-mutually exclusive mechanisms that can explain faster decisions in larger groups (Ioannou, 2017b). Firstly, individuals may make faster decisions when they are in groups due to a reduced perception of risk and/or greater perception of competition (Magurran \& Pitcher, 1983; Grand \& Dill, 1999), an effect which does not rely on information transfer between individuals. Such an effect is consistent with individuals in groups being bolder (i.e., less risk averse) and more active than solitary individuals (McDonald et al., 2016; Kareklas et al., 2018). Larger groups are also statistically more likely to contain individuals that make decisions more rapidly, for example because these individuals are less risk averse (i.e., are bolder (Ioannou \& Dall, 2016)), hungrier (Balaban-Feld et al., 2019), or better informed (Ioannou et al., 2015). If these individuals can disproportionately influence group decisions through leadership (Ioannou et al., 2011), decision speed can increase via this 'pool-of-competence' effect (Liker \& Bókony, 2009; Morand-Ferron \& Quinn, 2011; Bisazza et al., 2014). This mechanism relies on variation between individuals within the group and on faster decision makers disproportionally influencing the outcome, for example through greater confidence in their opinion (Marshall et al., 2017). Finally, frequent exchange of information with other individuals within groups can give rise to collective or swarm intelligence (Garnier et al., 2007). Here, information is pooled from multiple individuals in a decentralised manner (Ward et al., 2011; Berdahl et al., 2013; Sasaki et al., 2013) and is a mechanism that assumes minimal variation between individuals. Thus, it is associated with more evenly distributed, egalitarian decision making in contrast to the pool-of-competence effect.

As a social prey species, the Trinidadian guppy (Poecilia reticulata) presents a key opportunity to study how the effect of group size on decision 
making speed can vary with ecological conditions, particularly long-term exposure to predation. The guppy's morphology, life history and behaviour are well known to vary with the degree of risk from predatory fish (Magurran, 2005). In multiple river catchments in the Northern Range mountains of Trinidad, colonisation by predatory fish in upstream stretches is limited by rapids and waterfalls, generating distinct high (downstream) and low (upstream) predation habitats for the guppies that live throughout the rivers (Deacon et al., 2018). A number of studies have shown guppies from high predation habitats show a greater social tendency and form larger groups (Seghers, 1974; Magurran et al., 1992; Huizinga et al., 2009), and more recently, guppies from high and low predation populations have been shown to differ in other collective behaviours such as their collective motion (HerbertRead et al., 2017) and how they make decisions collectively (Ioannou et al., 2017; Herbert-Read et al., 2019). Previous studies have shown improved accuracy by pairs of guppies versus single individuals under standardised conditions (Bisazza et al., 2014), and by naturally occurring groups versus single individuals in situ (Clément et al., 2017). Clément et al. (2017) also showed that although group size had a positive effect on the accuracy of initially distinguishing between correct and incorrect foraging stimuli in both high and low predation habitats, once focal individuals had already approached one of the stimuli and made their first decision, subsequent decisions were more accurate when in a group compared to being alone only in low predation sites.

In our study, we used wild-caught guppies to explore how the speed of decision making is affected by group size in fish from high and low predation habitats tested under the same conditions. Shoals of guppies were tested in a Y-maze that was novel to the fish, a design which allows decisions and their speed to be easily quantified (Ward et al., 2011; Bevan et al., 2018). We used two measures of decision making speed: the time taken for the fish to leave the start area and reach the junction in the maze, and the time taken for the fish at the junction to make their first decision. The first of these is a decision only regarding when to move, and allows for a compromise between group members to be reached (McDonald et al., 2016). This is also a measure of boldness or exploration which we predict will increase with group size because individuals' perception of risk generally decreases in larger groups and/or because larger groups are more likely to contain at least some bold/exploratory individuals. The choice of which arm to move into 
also, however, requires synchronisation of movement destination which is mutually exclusive as it necessitates that only one of the possible options be chosen (Conradt, 2012). By testing shoals of fish from low and high predation habitats at different group sizes, the group size $\times$ predation risk interaction term in the statistical models tests whether group size affects decision making differently depending on whether fish are from high or low predation risk habitats. We predicted that larger groups would be faster in both contexts (Ward et al., 2011; McDonald et al., 2016), with the effect of group size being more pronounced in fish from low predation habitats based on previous work (Clément et al., 2017).

By tracking the movements of individual fish as they made their decision in these trials, we have previously shown that decisions are less egalitarian in fish from low predation habitats (Herbert-Read et al., 2019). Because of this difference in how decisions are made, the mechanism driving different decision times in low versus high predation fish can be inferred. If group size is more important in decision making in fish from low (versus high) predation habitats (Clément et al., 2017), then the mechanism for faster decision speed in larger groups is more likely to be the pool-of-competence effect. In contrast, a greater effect of group size in fish from high predation habitats would be more likely to be driven by a collective/swarm intelligence effect, as decision making is more egalitarian in high predation fish (Herbert-Read et al., 2019).

\section{Materials and methods}

\subsection{Study subjects and husbandry}

Female guppies were caught using a seine net from sites in the Northern Range mountains of Trinidad (Table 1). The classification as low or high predation is based on the absence (low) or presence (high) of Crenicichla frenata, the major predator of adult guppies (Deacon et al., 2018). Holding and testing pools were located in an outdoor enclosure at the University of the West Indies, St. Augustine campus. Approximately 90 fish from a single site were kept in each 120 -cm-diameter holding paddling pool, with a water depth of $10-13 \mathrm{~cm}$. Fish were kept for $>48$ hours before testing and fed standard tropical flake food ad libitum; fish were not fed on the day of testing until all trials were complete for that day to standardise hunger. Stock pools were drained and cleaned between stocking fish from different populations. 
Table 1.

The location of sites fish were caught from, their classification as high or low predation, and the number of trials $(N)$ conducted per group size using fish from that site.

\begin{tabular}{lcccrrr}
\hline \multirow{2}{*}{ River } & Longitude & Latitude & Predation risk & \multicolumn{3}{c}{ Group size } \\
\cline { 5 - 7 } & & & & $N=2$ & $N=4$ & $N=8$ \\
\hline Arima & $10: 41.58$ & $-61: 17.54$ & High & 10 & 10 & 10 \\
Lower Guanapo & $10: 38.40$ & $-61: 14.94$ & High & 9 & 9 & 9 \\
Lower Lopinot & $10: 41.71$ & $-61: 19.26$ & High & 10 & 10 & 10 \\
Paria & 10.44 .75 & $-61: 15.67$ & Low & 8 & 7 & 8 \\
Tacarigua & $10: 41.40$ & $-61: 21.51$ & High & 10 & 10 & 10 \\
Upper Guanapo & $10: 42.69$ & $-61: 16.04$ & Low & 10 & 10 & 10 \\
Upper Lopinot & $10: 42.95$ & $-61: 19.28$ & Low & 10 & 10 & 10 \\
Upper Turure & $10: 41.20$ & $-61: 10.30$ & Low & 10 & 10 & 10 \\
\hline
\end{tabular}

Stock pools were kept within $3 \mathrm{~m}$ of the testing pool, and all pools were under shade from trees between 0800 and 1400, when trials were conducted. A clear polythene sheet suspended over the stock and test pools stopped rain falling on the pools throughout the study. All trials were carried out in July 2013 and fish were returned to their source sites after testing. All procedures using non-human animals were in accordance with national and institutional regulations on animal care and were approved by the University of Bristol Ethical Review Group (UIN/13/028).

\subsection{Experimental apparatus and protocol}

Fish of approximately the same body length were haphazardly caught from the stock pools and transferred to a $15 \times 15 \mathrm{~cm}$ transparent plastic box at the end of the stem of the Y-shaped maze (Figure 1). The maze was designed to have a long stem between the start area and the junction of the maze to accurately measure the time taken to reach the junction. A triangular patch of gravel was placed in the left arm of the maze to differentiate the two arms so that the fish needed to decide whether to swim into the arm with or without the gravel. Gravel was chosen as it is found across populations and is hence familiar to the fish, unlike, for example, food or another species of fish which vary in abundance both between and within high and low predation sites. The shape of the gravel patch was designed so that lines of sight to the patch defined a 'decision zone' where the fish could see both the gravel patch and the equivalent empty space in the other arm (Figure 1). After 2 minutes 


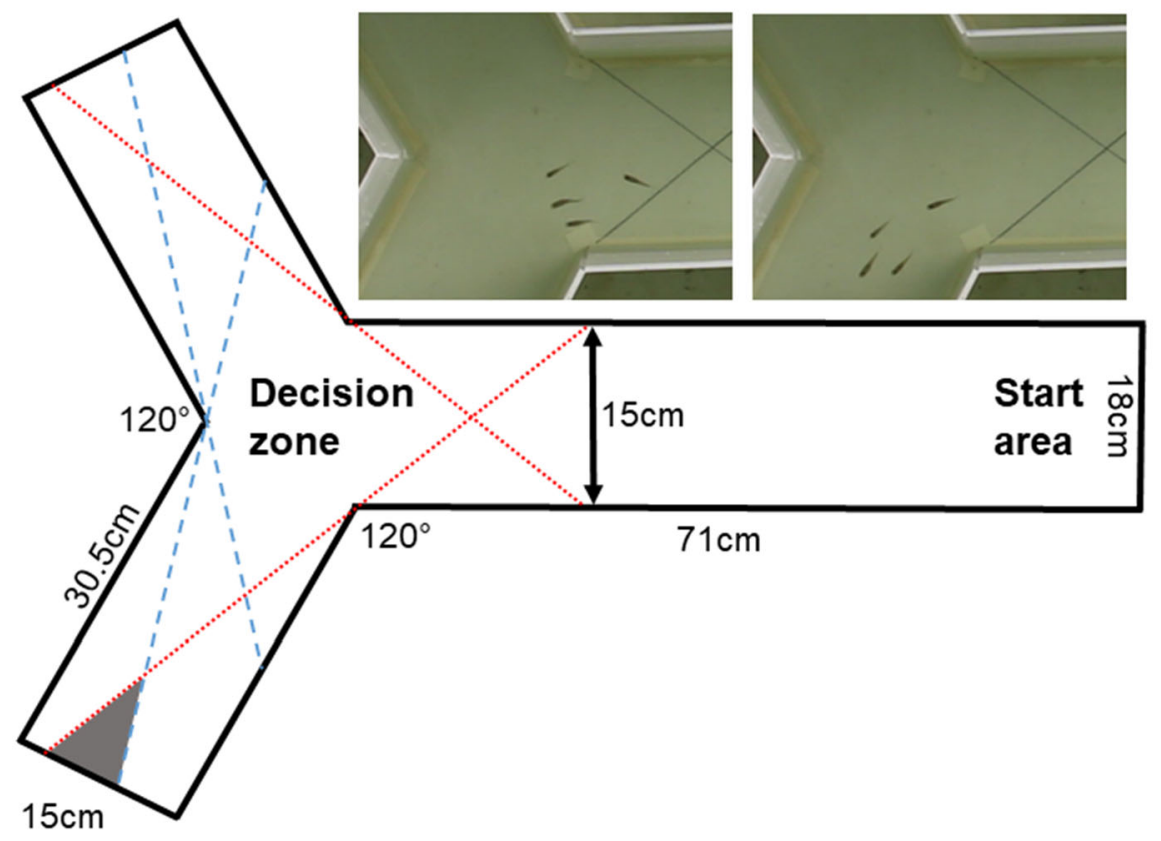

Figure 1. The experimental arena. Water depth in the maze was $11 \mathrm{~cm}$ at the stem of the $\mathrm{Y}$ where the fish were released and increased gradually to $12.5 \mathrm{~cm}$ at the end of each arm. White plastic boards underneath the maze ensured the base was flat and provided a highcontrast background to the fish to facilitate data collection from videos. Fish were released in the start area and the time then taken to reach the decision zone was recorded. We defined the decision zone as the junction of the maze and based this on the possible lines of sight to the gravel patch (the dark triangle in the figure in the left arm), or the equivalent empty space in the right arm. Reaching the decision zone was defined by the fish having a line of sight to both the gravel in one arm and the equivalent empty space at the end of the other (crossing both the red dotted lines). Making a choice into one of these arms was then defined as the point where the gravel/empty space in the other arm was no longer visible (crossing a blue dashed line). The insets show an example of a group of size 4 swimming through the decision zone.

of acclimatisation in the start area, recording at $25 \mathrm{fps}$ and a resolution of $1920 \times 1080$ was started using a Canon 550D DSLR camera mounted $1.25 \mathrm{~m}$ above the base of the paddling pool, and the box was raised remotely. As the box surrounded the fish before it was raised, raising it would be visually conspicuous to the fish regardless of their orientation (unlike raising a door between the fish and the decision zone: Bevan et al., 2018); movement of the water around the fish would also be detected via their lateral line. Differences in the orientation of the fish between trials may however have added noise to 
the time taken to reach the decision zone, although the transparency of the box makes it likely that the fish would have gained some knowledge of their position relative to the stem of the maze during the acclimatisation period. Recording took place until the fish made a choice as to which arm of the maze to visit first, after swimming through the decision zone. Fish were then removed and not retested. Group sizes were tested using a complete random block, i.e., so that each group size was tested in a block of 3 consecutive trials, but the order of testing was randomised within each block. A total of 1074 fish were tested in 230 trials, the number of trials in each group size and population combination are given in Table 1.

\subsection{Video analysis}

The time taken for the first fish to enter the decision zone from the start of the trial (i.e., from when the box was raised), and the time taken for the first fish to enter an arm from when the decision zone was first entered (i.e., time spent in the decision zone, Figure 1), were measured from the videos to the nearest second. The time taken to reach the decision zone is a measure of decision speed that allows compromise between group members and is often used as a measure of boldness or exploration (Bevan et al., 2018), while the time spent in the decision zone before a decision is made is a measure of decision making speed between mutually exclusive options (Ward et al., 2011). We measured the time taken for the first fish to enter these zones because the order in which individuals within a group make decisions has an important effect on decision making speed as social information becomes available once individuals start to respond (MacGregor et al., 2020). This is because an individual who has already decided and moved, even inadvertently, feeds back information to other group members, for example that it is less likely there is a predator waiting to strike. In addition to this information, the presence of another individual in an area can reduce the perception of risk associated with moving to that area due to the anti-predatory benefits of grouping (Ioannou, 2017a), which also changes the trade-off in whether to move there or not. These factors are particularly important to consider if group size is variable: as group size increases, a greater proportion of the group has social information available before committing to a decision, thus the decision speed of a randomly selected individual or the average speed across individuals is likely to change with group size due to the change in available information, rather than a greater information processing capacity 
of larger groups. As our study is focused on this information processing in collective decisions, using data on the first individual to make decision is thus unconfounded by these issues. Additionally, in groups such as fish shoals which are typically led from the front of the group (Bumann \& Krause, 1993), the cost of making a poor decision is greatest for the leading individual as they are most at risk from predators (Ioannou et al., 2019). Thus, making a correct decision is most important for the individual to make the first decision.

Body lengths of each fish were measured from the videos using still images as the fish passed through the decision zone (directly below the camera) and converted to centimetres based on dimensions of known length in the video images. Although the experimental trials could not be conducted with the experimenters being blind to the source population, data collection from the videos was blinded with regards to source population.

\subsection{Statistical analysis}

All statistical analyses were carried out in $\mathrm{R}$ version 3.6.0 ( $\mathrm{R}$ Core Team, 2017), and data are available in Table A1 at 10.6084/m9.figshare.13019834. The time taken to reach the decision zone from the start of the trial was analysed as a function of group size, predation level (high or low) and the group size $\times$ predation interaction using a negative binomial Generalised Linear Mixed Model (GLMM with the glmmTMB function in the glmmTMB package version 1.0.2.1; Brooks et al., 2017). The time spent in the decision zone before the first fish chose one of the arms was also analysed using a negative binomial GLMM with the same explanatory variables; a polynomial (quadratic) group size effect was also included after visually inspecting the trends. This analysis was then repeated for fish from high and low predation sites separately to further explore whether the high and low predation sites differed in which explanatory variables affected the time spent in the decision zone (the predation level term was removed from the models).

As the body size of fish can affect the time taken to move through space due to its effect on swimming speed (Fulton \& Bellwood, 2004) or boldness (Brown et al., 2007), to control for these possible effects the mean body length of the fish in each group was calculated and included as a main effect in the models. Population was included as the random intercept in all models. The assumption that the overdispersion statistic was approximately equal to 1 (i.e., between 0.5 and 2) (Thomas et al., 2015) was tested using 
equivalent negative binomial GLMs without the random term. GLMM models were compared using the corrected Akaike information criterion (AICc) using the ICtab function in the bbmle package version 1.0.20 (Bolker \& R Development Core Team, 2017). Models with lower AICc scores are more likely, providing a better fit to the data after penalisation for the number of parameters. A difference between two models in AICc of $>2$ units implies strong support for one model over the other (Burnham \& Anderson, 2002).

\section{Results}

\subsection{Time taken to reach the decision zone}

The model comparisons provided some support for the model with an interaction between group size and predation level as this model was 1.8 AICc units more likely than the model with main effects only (Table 2). Group size had a stronger negative effect on the time taken from the start of the trials to reach the decision zone in fish from low predation habitats (Figure 2). However, models without group size were substantially less likely than those with group size, and the most likely model included group size but not predation (Table 2), demonstrating the importance of group size rather than predation in determining the time taken to reach the decision zone (Figure 2). Removing the mean body length term from the main-effects only model reduced the AICc by only 0.4 units, suggesting it did not have a strong effect on the time taken (Table 2).

Table 2.

Model structures and model comparisons based on the AICc explaining the variance in the time to reach the decision zone using negative binomial GLMMs.

\begin{tabular}{lcr}
\hline Explanatory variables & $\Delta$ AICc & df \\
\hline Group size + mean SBL & 0 & 5 \\
Group.size $*$ Predation + mean SBL & 0.2 & 7 \\
Group.size + Predation + mean SBL & 2.0 & 6 \\
Group.size + Predation & 2.4 & 5 \\
Null (no explanatory variables) & 37.4 & 3 \\
Predation + mean SBL & 38.2 & 5 \\
\hline
\end{tabular}

SBL is the standard body length of the fish. 


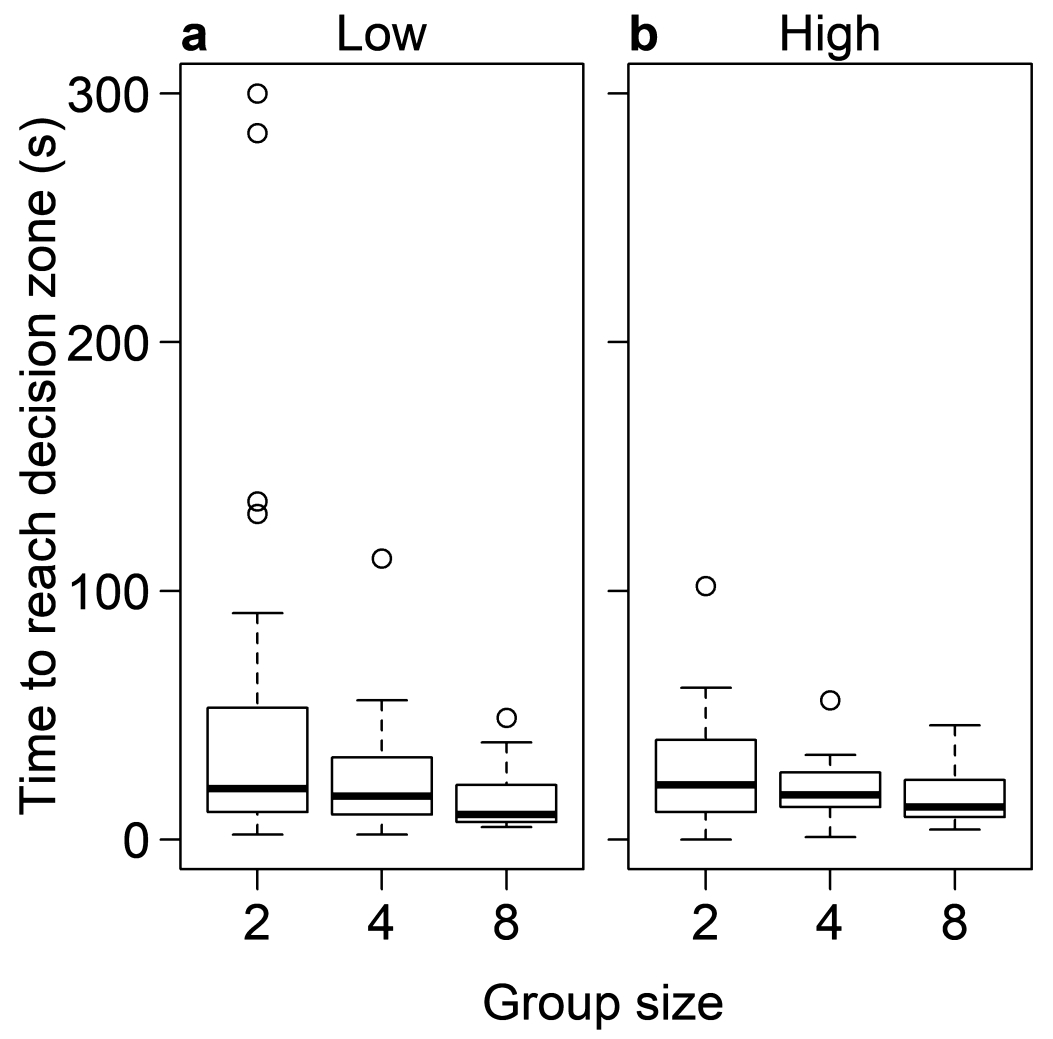

Figure 2. The effect of group size on the time taken to reach the decision zone from the start of the trial in fish from low (a) and high (b) predation habitats. Medians are represented by the thick black lines, interquartile ranges by the boxes, the whiskers represent the most extreme data points within $1.5 \times$ of the interquartile range, and the circles show data points beyond the whiskers.

\subsection{Time in the decision zone}

For the time spent in the decision zone, the model with the interaction between predation and the polynomial effect of group size was the most likely model given the data by at least 4 AICc units (Table 3). The effect of group size on the time taken to make a decision, when including a non-linear effect of group size, depended on whether fish were from high versus low predation habitats (Figure 3). To explore this dependency on predation further, trials of fish from each level of predation were analysed separately. There was no effect of group size or mean body size in fish from high predation sites as the null model that lacked explanatory variables was the most likely model 
Table 3.

Model structures and model comparisons based on the AICc explaining the variance in the time spent in the decision zone using negative binomial GLMMs.

\begin{tabular}{llcl}
\hline Data & Explanatory variables & $\Delta$ AICc & df \\
\hline All data & Group.size ${ }^{2} *$ Predation + mean SBL & 0 & 9 \\
& Group.size + mean SBL & 4.0 & 5 \\
& Group.size $*$ Predation + mean SBL & 5.4 & 7 \\
& Group.size + Predation + mean SBL & 5.7 & 6 \\
& Group.size + Predation + mean SBL & 6.5 & 7 \\
& Predation + mean SBL & 13.1 & 5 \\
& Group.size + Predation & 15.2 & 5 \\
High predation sites & Null (no explanatory variables) & 22.3 & 3 \\
& Null (no explanatory variables) & 0 & 3 \\
& Group.size & 0.7 & 4 \\
& mean SBL & 2.0 & 4 \\
& Group.size + mean SBL & 2.7 & 5 \\
Low predation sites & Group.size ${ }^{2}+$ mean SBL & 2.9 & 6 \\
& Group.size ${ }^{2}+$ mean SBL & 0 & 6 \\
& Group.size + mean SBL & 3.9 & 5 \\
& mean SBL & 9.3 & 4 \\
& Group.size & 13.5 & 4 \\
& Null (no explanatory variables) & 19.9 & 3 \\
\hline
\end{tabular}

SBL is the standard body length of the fish.

(Table 3). In trials of fish from low predation sites, however, the most likely model included the polynomial effect of group size (Table 3 ), where groups of 4 individuals were more rapid in making a decision than groups of 2 or 8 (Figure 3). In these low predation site trials, models with mean body length were more likely than those without this variable, implying that mean body length was also important in determining the time spent in the decision zone in fish from low predation sites (Table 3). Shoals of larger fish spent longer in the decision zone before making a decision (Figure 4).

\section{Discussion}

Our experiment shows that the speed of decision making is affected by group size in fish from low predation habitats more than in fish from high predation habitats, at least in small groups from 2 to 8 individuals. The time taken to reach the decision zone followed the expected direction that larger groups 


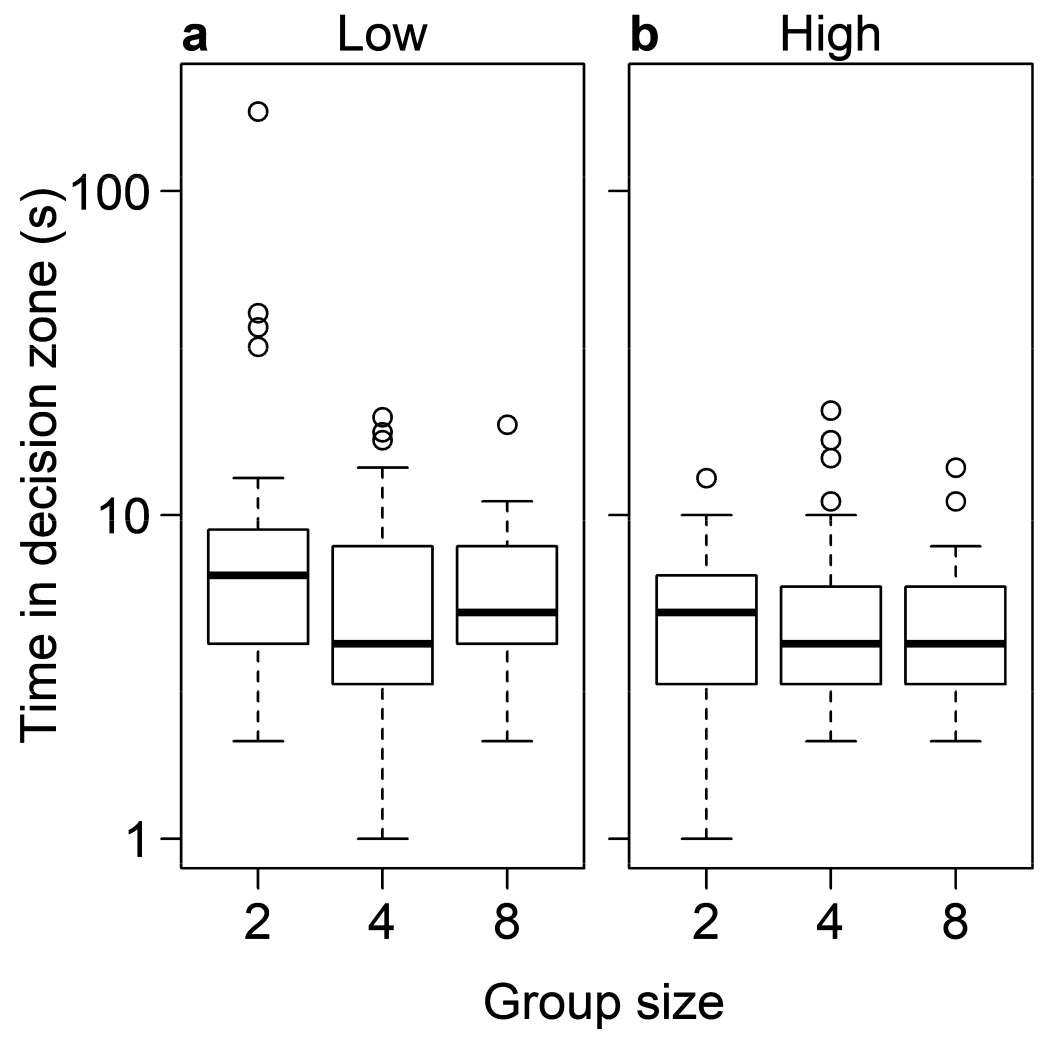

Figure 3. The effect of group size on the time taken in the decision zone before choosing one of the arms of the maze in fish from low (a) and high (b) predation habitats. Medians are represented by the thick black lines, interquartile ranges by the boxes, the whiskers represent the most extreme data points within $1.5 \times$ of the interquartile range, and the empty circles show data points beyond the whiskers.

were quicker to leave the start area, and hence were bolder and more exploratory than smaller groups (McDonald et al., 2016; Kareklas et al., 2018). There was some indication that this group size effect was reduced in fish from high predation sites. This may be explained by poecilids from higher predation sites being bolder when tested alone by emerging from a refuge more quickly (Brown et al., 2005; Harris et al., 2010). If fish are bold even when alone or in small groups ( 2 fish in our study), it is less likely that they will be even bolder in larger groups ( 4 or 8 in our study). Thus, a reduced effect of group size in high predation fish may be because they are individually relatively bold compared to those from low predation sites (Brown et 


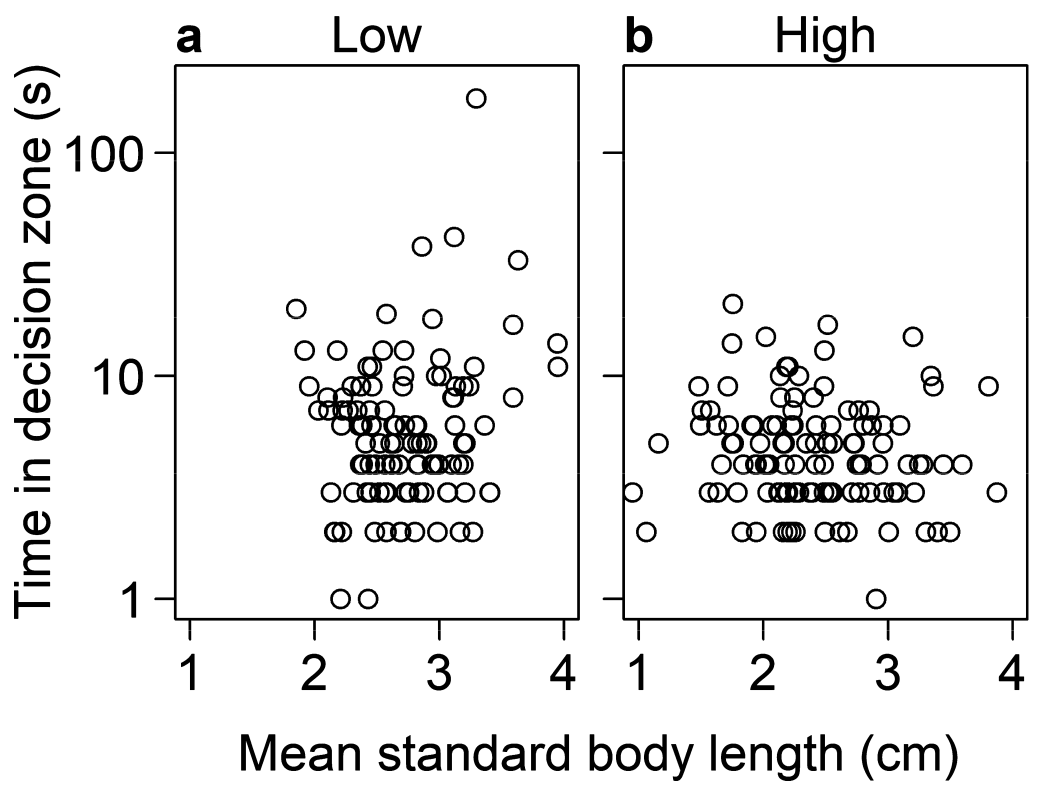

Figure 4. The effect of mean body length in the shoal on the time taken in the decision zone before choosing one of the arms of the maze in fish from low (a) and high (b) predation habitats.

al., 2005; Harris et al., 2010). The most important effect on the time taken to reach the decision zone was however group size and not predation, with a steady decrease in the time taken as group size increased for both high and low predation fish. This greater exploratory tendency in larger groups is likely to have ecological consequences, such as the rate at which groups encounter predators (Anholt et al., 2000) and resources (Ioannou et al., 2008) in their environment. The effect of group size may have been magnified by the novel environment of the arena, with a high contrast background being unfamiliar and inducing stress in the fish. With repeated exposure to such conditions, the effect of group size may weaken as fish even in small groups acclimatise to the test conditions.

When groups reached the decision zone, the effect of group size on the time taken to then make a choice between the two arms showed a different response compared to the time taken to reach the decision zone. In fish from high predation habitats, there was no effect of group size, while in low predation fish, the reduction in the time taken was still evident when group size was increased from 2 to 4 , but decision time then increased in groups of 8 . 
The effect of group size appears to depend on context, having a linear and decreasing effect on the time taken for fish to decide to leave the start area and explore (a decision regarding 'when' to initiate a behaviour), and a different effect on the decision of which arm to select (a 'when' and 'where' decision). These two contexts differ in whether compromise is possible (Conradt, 2012), and it has been suggested that individuals might use different social strategies depending on the extent compromise can occur. For example, decision making may be more shared (egalitarian) between individuals when compromise is possible because the 'average' of the individuals opinions can be used as the group's decision (Conradt, 2012). A change in social strategy from the decision to reach the decision zone to the decision made within the decision zone may explain why the effect of group size was similar between fish from low and high predation sites when reaching the decision zone but different between fish from these populations when deciding which arm to enter.

At the junction of the Y-maze where the fish had to make a decision about which arm to enter, finding that speed was greatest at the intermediate group size in fish from low predation habitats and that group size does not appear to have an effect in fish from high predation habitats contradicts experiments in sticklebacks (Gasterosteus aculeatus) where speed increased as group size increased up to at least 16 individuals (Ward et al., 2011). Ward et al. (2011) also used a Y-maze apparatus but with a model predator in one of the arms. In larger groups of sticklebacks and in a different context (the time to leave an unfavoured patch), however, decision speed is on average fastest at intermediate group sizes of around 16-17 individuals (Ward $\&$ Webster, 2019). Detection of food cues can be maximised at intermediate group sizes, for example in shoals of zebrafish Danio rerio (Steele et al., 1991), and there can be interference between individuals when group size or density becomes too high (Ranta \& Juvonen, 1993; Cvikel et al., 2015). Modelling also demonstrates that intermediate group sizes may be optimal in some situations (Codling et al., 2007; Kao \& Couzin, 2014). These studies suggest that when group size exceeds an upper limit, too many individuals can hamper decision making. Intermediate group sizes may be optimal if group size influences the proportion of individuals with some information versus those with none. In a scenario such as a Y-maze, those at the front of the shoal can view the two arms of the maze before those behind. It is 
unlikely in groups such as fish shoals that individuals are aware of the information held by others, so that decision making by the leading fish at the front of a shoal may be delayed by waiting for a response from uninformed individuals behind. As larger groups are spread over a larger area, there will be more uninformed individuals in larger groups, thus slowing the decision making of leading individuals more than in smaller groups with fewer (or no) uninformed individuals. The optimal group size may vary between species, the degree of conflicting opinions, and, as shown in our study, depend on the decision-making context and the ecological conditions the test animals originate from. While studies in non-human animals (for example, golden shiners Notemigonus crysoleucas (Berdahl et al., 2013), guppies Poecilia reticulata (Bisazza et al., 2014; Clément et al., 2017), goldfish Carassius auratus and minnows Phoxinus phoxinus (Pitcher et al., 1982), house sparrows Passer domesticus (Liker \& Bókony, 2009), and great tits Parus major and blue tits Cyanistes caeruleus (Morand-Ferron \& Quinn, 2011)) have usually demonstrated positive effects of group size on decision making and focused on the mechanisms that result in such effects, it is well established in the human psychology and social science literature that groups and social interactions can hamper decision making (Lorenz et al., 2011; Koriat, 2012; Minson \& Mueller, 2012).

Together with an analysis of the fish trajectories that shows deciding between the arms of the maze is more egalitarian in fish from high predation habitats (Herbert-Read et al., 2019), the result that group size matters more in fish from low predation habitats implies that the faster decision making in intermediately sized groups is driven by a pool-of-competence effect rather than collective/swarm intelligence (Ioannou, 2017b). As collective/swarm intelligence relies on more egalitarian decision making, we would expect a greater improvement with increased group size in the fish that made more egalitarian decisions (those from high predation sites). Instead we found no evidence that when at the junction in the maze, group size had any effect on decision making speed in fish from high predation habitats. These results provide further evidence that improved decision making in small shoals of fish is more likely to be driven by a pool-of-competence effect than collective/swarm intelligence (Bisazza et al., 2014; Ioannou, 2017b).

Collective behaviour has a major effect in the risk of being eaten (Bazazi et al., 2010; Bauer et al., 2015). While some mechanisms that cause individuals to be safer from predators in groups do not rely on group-level decision 
making or information transfer, such as the dilution and confusion effects (Foster \& Treherne, 1981; Duffield \& Ioannou, 2017), improved decision making by groups can act to further reduce the risk of predation (Magurran et al., 1985; Godin et al., 1988; Ward et al., 2011). Little attention has been given to how ecological factors affect group decision making or collective behaviour more generally (Chamberlain \& Ioannou, 2019; Tidau \& Briffa, 2019; Ginnaw et al., 2020), and only a handful of studies have examined how collective decision making changes with predation risk (Ioannou et al., 2017; Herbert-Read et al., 2019). Despite the differences between this study and that of Clément et al. (2017), the general trend found here, that group size was more important in decision speed in fish from low predation habitats, supports their findings. Together, our results with Clément et al. (2017) imply that the long-term exposure to predation that selects for larger groups (Seghers, 1974; Magurran et al., 1992; Herbert-Read et al., 2017) does not appear to be related to the importance of group size in decision making, a counter-intuitive finding that deserves further study.

\section{Data availability}

The data supporting the findings of this study are available as Table A1 at 10.6084/m9.figshare.13019834.

\section{Acknowledgements}

We thank Kharran Deonarinesingh and Dr. Matthew Edenbrow for support and helpful discussions. This work was supported by a Natural Environment Research Council grants NE/K009370/1 and NE/P012639/1 awarded to C.C.I.

\section{References}

Anholt, B.R., Werner, E. \& Skelly, D.K. (2000). Effect of food and predators on the activity of four larval ranid frogs. - Ecology 81: 3509-3521.

Balaban-Feld, J., Mitchell, W.A., Kotler, B.P., Vijayan, S., Tov Elem, L.T. \& Abramsky, Z. (2019). State-dependent foraging among social fish in a risky environment. - Oecologia 190: 37-45.

Bauer, U., Federle, W., Seidel, H., Grafe, T.U. \& Ioannou, C.C. (2015). How to catch more prey with less effective traps: explaining the evolution of temporarily inactive traps in carnivorous pitcher plants. — Proc. Roy. Soc. Lond. B: Biol. Sci. 282: 20142675. 
Bazazi, S., Ioannou, C.C., Simpson, S.J., Sword, G.A., Torney, C.J., Lorch, P.D. \& Couzin, I.D. (2010). The social context of cannibalism in migratory bands of the mormon cricket. - PLoS ONE 5: e15118.

Berdahl, A., Torney, C.J., Ioannou, C.C., Faria, J.J. \& Couzin, I.D. (2013). Emergent sensing of complex environments by mobile animal groups. - Science 339: 574-576.

Bevan, P.A., Gosetto, I., Jenkins, E.R., Barnes, I. \& Ioannou, C.C. (2018). Regulation between personality traits: individual social tendencies modulate whether boldness and leadership are correlated. — Proc. Roy. Soc. Lond. B: Biol. Sci. 285: 20180829.

Bisazza, A., Butterworth, B., Piffer, L., Bahrami, B., Petrazzini, M.E.M. \& Agrillo, C. (2014). Collective enhancement of numerical acuity by meritocratic leadership in fish. - Sci. Rep. 4: 4560.

Bolker, B.M. \& R Development Core Team (2017). bbmle: Tools for general maximum likelihood estimation. Available online at https://cran.r-project.org/web/packages/bbmle/ index.html.

Brooks, M.E., Kristensen, K., van Benthem, K.J., Magnusson, A., Berg, C.W., Nielsen, A., Skaug, H.J., Machler, M. \& Bolker, B.M. (2017). glmmTMB balances speed and flexibility among packages for zero-inflated generalized linear mixed modeling. - R J. 9: 378-400.

Brown, C., Jones, F. \& Braithwaite, V. (2005). In situ examination of boldness-shyness traits in the tropical poeciliid, Brachyraphis episcopi. — Anim. Behav. 70: 1003-1009.

Brown, C., Jones, F. \& Braithwaite, V.A. (2007). Correlation between boldness and body mass in natural populations of the poeciliid Brachyrhaphis episcopi. — J. Fish Biol. 71: 1590-1601.

Bumann, D. \& Krause, J. (1993). Front individuals lead in shoals of three-spined sticklebacks (Gasterosteus aculeatus) and juvenile roach (Rutilus rutilus). — Behaviour 125: 189-198.

Burnham, K.P. \& Anderson, D.R. (2002). Model selection and multimodel inference: a practical information-theoretic approach. - Springer, New York, NY.

Chamberlain, A.C. \& Ioannou, C.C. (2019). Turbidity increases risk perception but constrains collective behaviour during foraging by fish shoals. - Anim. Behav. 156: 129-138.

Clément, R.J.G., Vicente-Page, J., Mann, R.P., Ward, A.J.W., Kurvers, R.H.J.M., Ramnarine, I.W., de Polavieja, G.G. \& Krause, J. (2017). Collective decision making in guppies: a cross-population comparison study in the wild. - Behav. Ecol. 28: 919-924.

Codling, E.A., Pitchford, J.W. \& Simpson, S.D. (2007). Group navigation and the "manywrongs principle" in models of animal movement. — Ecology 88: 1864-1870.

Conradt, L. (2012). Models in animal collective decision-making: information uncertainty and conflicting preferences. - Interface Focus 2: 226-240.

Cvikel, N., Egert Berg, K., Levin, E., Hurme, E., Borissov, I., Boonman, A., Amichai, E. \& Yovel, Y. (2015). Bats aggregate to improve prey search but might be impaired when their density becomes too high. - Curr. Biol. 25: 206-211.

Day, R.L., MacDonald, T., Brown, C., Laland, K.N. \& Reader, S.M. (2001). Interactions between shoal size and conformity in guppy social foraging. - Anim. Behav. 62: 917925. 
Deacon, A.E., Jones, F.A.M. \& Magurran, A.E. (2018). Gradients in predation risk in a tropical river system. - Curr. Zool. 64: 213-221.

Duffield, C. \& Ioannou, C.C. (2017). Marginal predation: do encounter or confusion effects explain the targeting of prey group edges? - Behav. Ecol. 28: 1283-1292.

Foster, W.A. \& Treherne, J.E. (1981). Evidence for the dilution effect in the selfish herd from fish predation on a marine insect. - Nature 293: 466-467.

Fulton, C.J. \& Bellwood, D.R. (2004). Wave exposure, swimming performance, and the structure of tropical and temperate reef fish assemblages. - Mar. Biol. 144: 429-437.

Garnier, S., Gautrais, J. \& Theraulaz, G. (2007). The biological principles of swarm intelligence. - Swarm Intell. 1: 3-31.

Ginnaw, G.M., Davidson, I.K., Harding, H.R., Simpson, S.D., Roberts, N.W., Radford, A.N. \& Ioannou, C.C. (2020). Effects of multiple stressors on fish shoal collective motion are independent and vary with shoaling metric. - Anim. Behav. 168: 7-17.

Godin, J.G.J., Classon, L.J. \& Abrahams, M.V. (1988). Group vigilance and shoal size in a small characin fish. — Behaviour 104: 29-40.

Grand, T.C. \& Dill, L.M. (1999). The effect of group size on the foraging behaviour of juvenile coho salmon: reduction of predation risk or increased competition?. - Anim. Behav. 58: 443-451.

Harris, S., Ramnarine, I.W., Smith, H.G. \& Pettersson, L.B. (2010). Picking personalities apart: estimating the influence of predation, sex and body size on boldness in the guppy Poecilia reticulata. - Oikos 119: 1711-1718.

Herbert-Read, J.E., Rosén, E., Szorkovszky, A., Ioannou, C.C., Rogell, B., Perna, A., Ramnarine, I.W., Kotrschal, A., Kolm, N., Krause, J. \& Sumpter, D.J.T. (2017). How predation shapes the social interaction rules of shoaling fish. — Proc. Roy. Soc. Lond. B: Biol. Sci. 284: 20171126.

Herbert-Read, J.E., Wade, A.S.I., Ramnarine, I.W. \& Ioannou, C.C. (2019). Collective decision-making appears more egalitarian in populations where group fission costs are higher. — Biol. Lett. 15: 20190556.

Huizinga, M., Ghalambor, C.K. \& Reznick, D.N. (2009). The genetic and environmental basis of adaptive differences in shoaling behaviour among populations of Trinidadian guppies, Poecilia reticulata. — J. Evol. Biol. 22: 1860-1866.

Ioannou, C.C. (2017a). Grouping and predation. - In: Encycl. evol. psychol. sci. (Shackelford, T.K. \& Weekes-Shackelford, V.A., eds). Springer International Publishing, Cham, p. $1-6$.

Ioannou, C.C. (2017b). Swarm intelligence in fish? The difficulty in demonstrating distributed and self-organised collective intelligence in (some) animal groups. - Behav. Processes 141: 141-151.

Ioannou, C.C., Couzin, I.D., James, R., Croft, D.P. \& Krause, J. (2011). Social organisation and information transfer in schooling fish. - In: Fish cognitive behaviour, 2nd edn. (Brown, C., Laland, K. \& Krause, J., eds). Wiley-Blackwell, Oxford, p. 217-239.

Ioannou, C.C. \& Dall, S.R.X. (2016). Individuals that are consistent in risk-taking benefit during collective foraging. - Sci. Rep. 6: 33991. 
Ioannou, C.C., Madirolas, G., Brammer, F.S., Rapley, H.A. \& de Polavieja, G.G. (2018). Adolescents show collective intelligence which can be driven by a geometric mean rule of thumb. - PLoS ONE 13: e0204462.

Ioannou, C.C., Ramnarine, I.W. \& Torney, C.J. (2017). High-predation habitats affect the social dynamics of collective exploration in a shoaling fish. - Sci. Adv. 3: e1602682.

Ioannou, C.C., Rocque, F., Herbert-Read, J.E., Duffield, C. \& Firth, J.A. (2019). Predators attacking virtual prey reveal the costs and benefits of leadership. - Proc. Natl. Acad. Sci. 116: 8925-8930.

Ioannou, C.C., Ruxton, G.D. \& Krause, J. (2008). Search rate, attack probability, and the relationship between prey density and prey encounter rate. - Behav. Ecol. 19: 842-846.

Ioannou, C.C., Singh, M. \& Couzin, I.D. (2015). Potential leaders trade off goal-oriented and socially-oriented behavior in mobile animal groups. - Am. Nat. 186: 284-293.

Kao, A.B. \& Couzin, I.D. (2014). Decision accuracy in complex environments is often maximized by small group sizes. — Proc. Roy. Soc. Lond. B: Biol. Sci. 281: 20133305.

Kareklas, K., Elwood, R.W. \& Holland, R.A. (2018). Grouping promotes risk-taking in unfamiliar settings. - Behav. Process. 148: 41-45.

Koriat, A. (2012). When are two heads better than one and why? - Science 336: 360-362.

Krause, J. \& Ruxton, G.D. (2002). Living in groups. — Oxford Univ. Press, Oxford.

Liker, A. \& Bókony, V. (2009). Larger groups are more successful in innovative problem solving in house sparrows. — Proc. Natl. Acad. Sci. USA 106: 7893-7898.

Lorenz, J., Rauhut, H., Schweitzer, F. \& Helbing, D. (2011). How social influence can undermine the wisdom of crowd effect. — Proc. Natl. Acad. Sci. USA 108: 9020-9025.

MacGregor, H.E.A., Herbert-Read, J.E. \& Ioannou, C.C. (2020). Information can explain the dynamics of group order in animal collective behaviour. - Nature Commun. 11: 2737.

Magurran, A.E. (2005). Evolutionary ecology: the Trinidadian guppy. — Oxford University Press, Oxford.

Magurran, A.E., Oulton, W.J. \& Pitcher, T.J. (1985). Vigilant behaviour and shoal size in minnows. — Z. Tierpsychol. 67: 167-178.

Magurran, A.E. \& Pitcher, T.J. (1983). Foraging, timidity and shoal size in minnows and goldfish. - Behav. Ecol. Sociobiol. 12: 147-152.

Magurran, A.E., Seghers, B.H., Carvalho, G.R. \& Shaw, P.W. (1992). Behavioural consequences of an artificial introduction of guppies (Poecilia reticulata) in N. Trinidad: evidence for the evolution of anti-predator behaviour in the wild. — Proc. Roy. Soc. Lond. B: Biol. Sci. 248: 117-122.

Marshall, J.A.R., Brown, G. \& Radford, A.N. (2017). Individual confidence-weighting and group decision-making. - Trends Ecol. Evol. 32: 636-645.

McDonald, N.D., Rands, S.A., Hill, F., Elder, C. \& Ioannou, C.C. (2016). Consensus and experience trump leadership, suppressing individual personality during social foraging. Sci. Adv. 2: e1600892.

Minson, J.A. \& Mueller, J.S. (2012). The cost of collaboration: why joint decision making exacerbates rejection of outside information. - Psychol. Sci. 23: 219-224.

Morand-Ferron, J. \& Quinn, J.L. (2011). Larger groups of passerines are more efficient problem solvers in the wild. — Proc. Natl. Acad. Sci. USA 108: 15898-15903. 
Pitcher, T.J., Magurran, A.E. \& Winfield, I.J. (1982). Fish in larger shoals find food faster. Behav. Ecol. Sociobiol. 10: 149-151.

R Core Team (2017). R: a language and environment for statistical computing. - R Foundation for Statistical Computing, Vienna.

Ranta, E. \& Juvonen, S.K. (1993). Interference affects food-finding rate in schooling sticklebacks. - J. Fish Biol. 43: 531-535.

Sasaki, T., Granovskiy, B., Mann, R.P., Sumpter, D.J.T. \& Pratt, S.C. (2013). Ant colonies outperform individuals when a sensory discrimination task is difficult but not when it is easy. — Proc. Natl. Acad. Sci. USA 110: 13769-13773.

Seghers, B.H. (1974). Schooling behavior in the guppy (Poecilia reticulata): an evolutionary response to predation. - Evolution 28: 486-489.

Steele, C.W., Scarfe, A.D. \& Owens, D.W. (1991). Effects of group size on the responsiveness of zebrafish, Brachydanio rerio (Hamilton Buchanan), to alanine, a chemical attractant. J. Fish Biol. 38: 553-564.

Tamm, S. (1980). Bird orientation: single homing pigeons compared with small flocks. Behav. Ecol. Sociobiol. 7: 319-322.

Thomas, R.J., Lello, J., Medeiros, R., Pollard, A., Robinson, P., Seward, A., Smith, J., Vafidis, J. \& Vaughan, I. (2015). Data analysis with R statistical software: a guidebook for scientists. - Eco-explore, Newport.

Tidau, S. \& Briffa, M. (2019). Anthropogenic noise pollution reverses grouping behaviour in hermit crabs. - Anim. Behav. 151: 113-120.

Ward, A.J.W., Herbert-Read, J.E., Sumpter, D.J.T. \& Krause, J. (2011). Fast and accurate decisions through collective vigilance in fish shoals. — Proc. Natl. Acad. Sci. USA 108: 2312-2315.

Ward, A.J.W. \& Webster, M.M. (2019). Mid-sized groups perform best in a collective decision task in sticklebacks. — Biol. Lett. 15: 20190335. 